\title{
c-Met affects gemcitabine resistance during carcinogenesis in a mouse model of pancreatic cancer
}

\author{
$\mathrm{KOZO} \mathrm{NOGUCHI}^{1,2^{*}}$, MASAMITSU KONNO ${ }^{2 *}$, HIDETOSHI EGUCHI $^{1 *}$, KOICHI KAWAMOTO ${ }^{1}$, \\ RYOUTA MUKAI $^{1}$, NAOHIRO NISHIDA ${ }^{2}$, JUN KOSEKI ${ }^{3}$, HIROSHI WADA ${ }^{1}$, HIROFUMI AKITA ${ }^{1}$, TAROH SATOH ${ }^{2}$, \\ SHIGERU MARUBASHI $^{1}$, HIROAKI NAGANO ${ }^{1}$, YUICHIRO DOKI $^{1}$, MASAKI MORI ${ }^{1}$ and HIDESHI ISHII ${ }^{2,3}$ \\ Departments of ${ }^{1}$ Gastroenterological Surgery, ${ }^{2}$ Frontier Science for Cancer and Chemotherapy, and \\ ${ }^{3}$ Medical Data Science, Graduate School of Medicine, Osaka University, Suita, Osaka 565-0871, Japan
}

Received December 18, 2015; Accepted February 28, 2018

DOI: $10.3892 / \mathrm{ol} .2018 .8793$

\begin{abstract}
Pancreatic adenocarcinoma is thought to develop from histologically identifiable intraductal lesions known as pancreatic intraepithelial neoplasias (PanINs), which exhibit similar morphological and genetic features to pancreatic ductal adenocarcinoma (PDAC). Therefore, a better understanding of the biological features underlying the progression of PanIN is essential to development more effective therapeutic interventions for PDAC. In recent years, numerous studies have reported that MET proto-oncogene receptor tyrosine kinase $(c-M E T)$ is a potential marker of pancreatic cancer stem cells (CSCs). CSCs have been revealed to initiate and propagate tumors in vitro and in vivo, and are associated with a chemoresistant phenotype. However, in vivo models using a xenograft approach are limited. In the present study, the morphological phenotype, molecular alteration and biological behavior of neoplasia in $\mathrm{Pdx}-1^{\mathrm{Cre} /+}, \mathrm{Kras}^{\mathrm{LSL}-\mathrm{GI2D/+}}$ and $\mathrm{Met}^{\text {flox/flox }}$ and wild-type mice was analyzed. The results demonstrated that while oncogenic Kras ${ }^{L S L-G 12 D /+}$ increased PanIN initiation and significantly decreased survival rate compared with wild-type mice, no additive effect of c-Met receptor signaling on PanIN progression or prognosis was observed. Following gemcitabine administration, c-Met inhibition in $\mathrm{Kras}^{\text {LSL-GI2D/+ }}$ mice significantly decreased the total surface area of PanIN lesions and the number of anti-proliferation marker protein Ki-67 positive cells occupying PanIN lesions compared with
\end{abstract}

Correspondence to: Professor Masaki Mori, Department of Gastroenterological Surgery, Graduate School of Medicine, Osaka University, 2-2 Yamadaoka, Suita, Osaka 565-0871, Japan

E-mail:mmori@gesurg.med.osaka-u.ac.jp

Professor Hideshi Ishii, Department of Medical Data Science, Graduate School of Medicine, Osaka University, 2-2 Yamadaoka, Suita, Osaka 565-0871, Japan

E-mail: hishii@gesurg.med.osaka-u.ac.jp

${ }^{*}$ Contributed equally

Key words: c-Met, Kras, pancreas, cancer, chemotherapy
$\mathrm{Met}^{+/+}$mice. In conclusion, complete inhibition of the c-Met signaling pathway with chemotherapy may be useful for the treatment of pancreatic cancer.

\section{Introduction}

Pancreatic cancer is the fourth leading cause of cancer-associated mortality in the United States (1). Despite recent advances in treatment, the 5-year overall survival rate for pancreatic cancer remains $<5 \%$ (2). This poor prognosis is considered to be due to the highly aggressive invasion and early metastasis that is typical of pancreatic cancer, with the majority of patients presenting with extrapancreatic dissemination at diagnosis (3).

Therefore, further understanding of the biological behavior, and molecular and genetic alterations, in the stepwise progression of pancreatic intraepithelial neoplasia (PanIN) in the development of pancreatic ductal adenocarcinoma (PDAC) is required. A previous study associated the MET proto-oncogene receptor tyrosine kinase ( $c$-MET), which functions in epithelial-mesenchymal transition (EMT), with PDAC. $c-M E T$ encodes for a membrane-bound receptor tyrosine kinase that is predominantly expressed by epithelial cells (4). Activation of c-Met occurs following its phosphorylation in response to the binding of its ligand, hepatocyte growth factor (HGF; also referred to as scatter factor), which results in the induction of a downstream signaling cascade (4). c-Met activating ligands are secreted by cells of mesenchymal origin (4). The resulting $\mathrm{HGF} / \mathrm{c}-\mathrm{Met}$ pleiotropic signaling pathway activates mediators of cell proliferation and motility (4). This signaling cascade has been associated with tumorigenesis following the identification of amplification, activating mutation and/or overexpression of $c-M E T$ in the majority of solid organ neoplasms (4). Histopathological evaluation of clinical samples from patients with PDAC has demonstrated that $c$-MET expression levels are increased by $\sim 5-7$-fold compared with those of normal pancreatic tissue samples, with this being proportional to the tumor grade and correlated with an increased tumor-node-metastasis stage (4). In addition, HGF protein secreted by surrounding stromal tissue has been correlated with $c-M E T$ overexpression in patients with pancreatic cancer, and is associated with a poorer overall survival (5). 
A growing body of evidence suggests that a hierarchy exists in cancer cell populations, a theory initially made in the study of hematopoietic malignancies (6). Cancer stem cells (CSCs) comprise a small minority of tumor cells; however, they appear to be the only cancer cell type capable of unlimited self-renewal and formation of xenografts. Interestingly, CSCs appear to have a limited potential for further differentiation (6). The majority of patients with PDAC are only candidates for palliative chemotherapy, which has been proven to be largely ineffective at halting tumor progression (1). One proposed mechanism of pancreatic cancer cell resistance to palliative chemotherapy involves the signaling pathway of the EMT-associated protein c-Met, a signaling pathway that is essential for cancer cell proliferation and migration (4). In the present study, the role served by c-Met in the tumorigenesis and chemoresistance of KRAS proto-oncogene GTPase $(K R A S)^{\mathrm{G} 12 \mathrm{D}}$-induced PDAC was investigated, in addition to its potential as a therapeutic target for the treatment of PDAC.

\section{Materials and methods}

Mouse model of PDAC. All animal studies were approved by the Animal Experiments Committee of Osaka University (Osaka, Japan; approval no. 24-122-022). $P d x-1^{C r e /+}, K_{r a s}{ }^{L S L-G 12 D /+}$ and $M e t^{f l o x} / f \circ x$ adult transgenic mating pairs of male and female mice ( 2 of each type) from a BL6 background ( 6 weeks old; weight unknown) were obtained from the National Cancer Institute (National Institutes of Health, Bethesda, MD, USA). All experiments used co-housed littermates to ensure the consistency of microflora; the temperature was $\sim 22^{\circ} \mathrm{C}$ in $12 \mathrm{~h}$-cycle of light and dark, and food and water were added in ad libitum. The $P d x-1^{C r e /+}$ mice were crossed with $\mathrm{Kras}^{L S L-G 12 D /+}$ mice or Met flox/flox mice to generate $P d x-1^{\text {Crel+ }} / \mathrm{Kras}^{L S L-G 12 D /+}(\mathrm{Km})$ and $P d x-1^{\mathrm{Crel+}} / \mathrm{Met} \mathrm{flox}^{\text {flflox }}(\mathrm{M} \Delta$ ) mouse strains, respectively. The $\mathrm{Km}$ mice were crossed with $\mathrm{M} \Delta$ mice to generate the

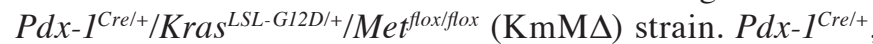

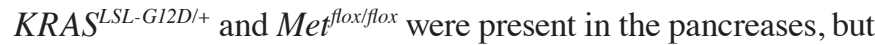
not tails, of compound mutant mice.

Genotyping. Mouse genomic DNA was isolated from tail biopsies. Briefly, to extract DNA, tail biopsy samples were incubated at $95^{\circ} \mathrm{C}$ in $25 \mathrm{mM} 10 \mathrm{~N} \mathrm{NaOH}$ and $0.2 \mathrm{mM}$ EDTA buffer ( $\mathrm{pH}$ 12.0), followed by neutralization with $1 \mathrm{M}$ Tris- $\mathrm{HCl}$ (pH 5.0) at $20^{\circ} \mathrm{C}$. After centrifuging at $300 \mathrm{x}$ g for $15 \mathrm{~min}$ at $4^{\circ} \mathrm{C}$, a total of $2 \mu \mathrm{l}$ of each sample supernatant underwent a polymerase chain reaction (PCR) using the PrimeSTAR Max PCR kit (Takara Bio, Ltd., Shiga, Japan) according to the manufacturer's protocol. PCR reaction was performed on the GeneAmp $^{\circledR}$ PCR System 9600 (Applied Biosystems; Thermo Fisher Scientific, Inc., Waltham, MA, USA). Thermocycling conditions for $\mathrm{Pdx}-1^{\mathrm{Cre} /+}$ and $\mathrm{Kras}{ }^{\mathrm{LSL}-\mathrm{G} 12 \mathrm{D} /+}$ samples were as follows: $94^{\circ} \mathrm{C}$ for $2 \mathrm{~min} ; 35$ cycles of $94^{\circ} \mathrm{C}$ for $30 \mathrm{sec}$, $60^{\circ} \mathrm{C}$ for $30 \mathrm{sec}$ and $72^{\circ} \mathrm{C}$ for $30 \mathrm{sec}$; and $72^{\circ} \mathrm{C}$ for $5 \mathrm{~min}$. Thermocycling conditions for Met flox/flox $^{\text {samples were as }}$ follows: $94^{\circ} \mathrm{C}$ for $2 \mathrm{~min}$; 45 cycles of $94^{\circ} \mathrm{C}$ for $30 \mathrm{sec}, 54^{\circ} \mathrm{C}$ for $30 \mathrm{sec}$ and $72^{\circ} \mathrm{C}$ for $30 \mathrm{sec}$; and $72^{\circ} \mathrm{C}$ for $5 \mathrm{~min}$. PCR was performed using the following primer pairs (https://www. jax.org/): (https://www.jax.org/): $P d x-1^{\text {Crel+ }}$ forward (F), 5'-GCGGTCTGGCAGTAAAAACTATC-3' and reverse (R), 3'-GTGAAACAGCATTGCTGTCACTT-5'; Kras ${ }^{L S L-G 12 D}$
Y-116 F: 5'-TCCGAA TTCAGT GACTAC AGATG-3'; $\mathrm{Kras}^{L S L-G 12 D}$ Y-117 F: 5'-CTAGCCACCATGGCTTGAGT-3'; $\operatorname{Kras}^{L S L-G 12 D}$ Y-118 R: 5'-ATGTCTTTCCCCAGCACAGT-3'; and $M e t^{\text {flox/flox }}$ F: 5'-TTAGGCAATGAGGTGTCCCAC-3' and R: 3'-CCAGGTGGCTTCAAATTCTAAGG-5'. An $8 \mu 1$ aliquot of each PCR product was separated on $2 \%$ agarose gel using electrophoresis and visualized with ethidium bromide staining.

Gemcitabine (GEM) treatment. Mice were injected with GEM (Sigma-Aldrich; Merck KGaA, Darmstadt, Germany) intra-peritoneally on days 1,8 and 15 . Mice were given $125 \mathrm{mg} / \mathrm{kg}$ GEM, or PBS as control, as previously described (7). Survival of the mice was observed until 400 days post-injection.

Immunohistochemistry (IHC). IHC was performed as previously described (8). Briefly, the pancreas was fixed with $10 \%$ formaldehyde, embedded in paraffin and cut into $4-\mu$ m-thick sections. The sections were subsequently deparaffinized in xylene, boiled for antigen retrieval and incubated with anti-c-Met (mouse monoclonal; 1:100 dilution) and anti-proliferation marker protein Ki-67 (Ki-67; rabbit polyclonal; 1:50 dilution) (both Abcam, Cambridge, UK) primary antibodies overnight at $4^{\circ} \mathrm{C}$. Following incubation with the rabbit (cat. no. PK4001) and mouse (cat. no. PK4002) secondary antibodies (both Vector Laboratories, Inc., Burlingame, CA, USA; dilution 1:1,000) for $2 \mathrm{~h}$ at $22^{\circ} \mathrm{C}$, these were then visualized with avidin-biotin complex reagents (ABC-HRP kit; Vector Laboratory, Inc., Burlingame, CA, USA) and 3,3'-diaminobenzidine. Serial sections were evaluated for each antibody under the light microscope. The alcian blue staining was performed using a kit (cat. no. H-3501; Vector Laboratories, Inc.) for $30 \mathrm{~min}$ at $22^{\circ} \mathrm{C}$ according to the manufacturer's protocol. Histology was performed using hematoxylin and eosin (H\&E) staining kits (hematoxylin; cat. no. 8650; Sakura Finetech, Tokyo, Japan] for $5 \mathrm{~min}$ and eosin (cat. no. 8659; Sakura Finetech) for $1 \mathrm{~min}$ at $22^{\circ} \mathrm{C}$ according to the manufacturer's protocol, and confirmed by two pathologists.

Quantification of PanIN progression. ImageJ software version 1.6.0_24 (National Institutes of Health;http:// rsbweb.nih.gov/ij) software was used for the manual detection of total tissue or individual acinar, ductal and parenchymal lesions (including acinar to ductal metaplasia, PanIN and invasive ductal adenocarcinoma). The total percentage of tissue surface area occupied by each lesion was calculated for 10 random fields of view for $\leq 3$ independent slides (8).

Statistical analysis. Results are presented as the mean \pm standard deviation unless otherwise indicated. Statistically significant differences were determined using a log-rank test (for survival rate using Kaplan-survival curves) or Student's t-test. $\mathrm{P}<0.05$ was considered to indicate a statistically significantly difference.

\section{Results}

Endogenous Kras ${ }^{G 12 D}$ expression induces early and advanced stage PanINs. Previous reports have demonstrated that oncogenic $\operatorname{Kras}^{G 12 D}$ induces the formation of ductal lesions that 
A
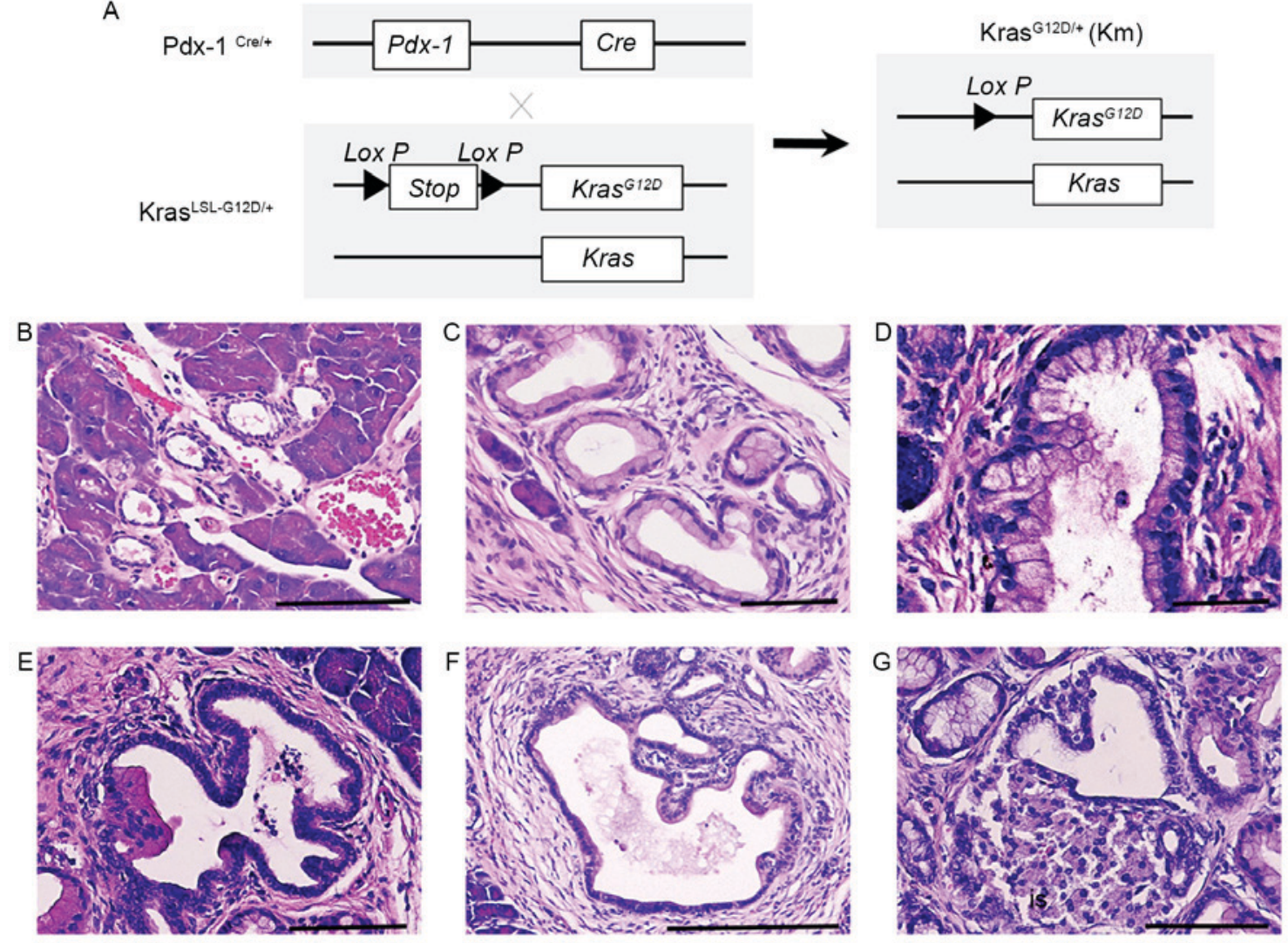

Figure 1. Oncogenic $K R A S^{G I 2 D}$ expression induces early to advanced stage PanIN. (A) Conditional heterozygous $K R A S^{L S L-G 12 D}$ allele is and generation of the expressed $K R A S^{G 12 D}$ allele following Cre recombination. Samples were stained with hematoxylin and eosin. (B) Cross section of normal pancreatic tissue from a wild-type mouse revealed a flat ductal epithelium monolayer. (C) PanIN-1A lesion composed of tall columnar cells with basally-located nuclei and abundant mucin glycoprotein. (D) PanIN-1B lesion exhibiting basally pseudostratified structures, but otherwise identical to PanIN-1A. (E) PanIN-2 lesion exhibiting a marked loss of polarity and moderate nuclear atypia. (F) PanIN-3 lesion with complete loss of cellular polarity, marked nuclear atypia and cell clusters budding into the ductal lumen. (G) Pancreatic ductal adenocarcinoma exhibiting a tendency to invade adjacent structures, including islets. Scale bar, $100 \mu \mathrm{m}$. PanIN, pancreatic intraepithelial neoplasia; KRAS, KRAS proto-oncogene GTPase; PDX-1, pancreatic and duodenal homeobox 1.

recapitulate the development of human pancreatic neoplastic lesions in $P d x-1^{C r e} / \operatorname{Kras}^{L S L-G 12 D /+}$ mutant mice (9). The pancreas of $\mathrm{Pdx}-1^{\mathrm{Cre}} / \mathrm{Kras}^{\mathrm{LSL}-\mathrm{GI2D/+}}$ mutant mice developed ductal lesions that represented all three stages of human PanIN lesions (Fig. 1). Normal pancreatic tissues from wild-type control mice (CTL) revealed a normal cuboidal ductal epithelium monolayer, islet cells and surrounding acinar tissue (Fig. 1B). Low-grade PanIN lesions (PanIN-1) were composed of flat or papillary columnar or cuboidal cells that retained their nuclear polarity and lacked atypical nuclei (Fig. 1B). Intermediate-grade PanIN lesions (PanIN-2), which are more architecturally complex compared with PanIN-1 lesions, presented nuclear abnormalities, including loss of polarity, crowding, variable size (pleomorphism), hyperchromasia and pseudo-stratification; however, the presence of mitoses were rare (Fig. 1C). High-grade PanIN lesions (PanIN-3) displayed a widespread loss of polarity, marked nuclear atypia and prevalent mitoses within the basement membrane (Fig. 1D). Histological study revealed that PanIN-2 lesions had a marked loss of polarity and moderate nuclear atypia (Fig. 1E) and that PanIN-3 lesions had a complete loss of cellular polarity, marked nuclear atypia and cell clusters budding into the ductal lumen (Fig. 1F). Histological study also demonstrated that PDAC had the tendency to invade adjacent structures, including islets (Fig. 1G). These results indicate that KRAS activating mutations induce the progression of PanIN.

Successful targeted deletion of c-MET in the pancreas of $\mathrm{Km}$ mice. To examine the potential role of c-Met in the development of PDAC, $\mathrm{Km}$ mice were crossed with $\mathrm{M} \Delta$ mice to generate KmM $\Delta$ mice (Fig. 2A). This excised the $c$-MET gene as part of a Cre-mediated silencing cassette and subsequent recombination generated by a single Lox $\mathrm{P}$ site was detected in all mice. The resulting strain with floxed $c-M E T$ alleles was utilized for breeding with strains harboring the $P d x-I^{\text {Cre }}$ and the constitutively active $\operatorname{Kras}^{L S L-G 12 D}$ knock-in allele (Fig. 2B). Immunostaining identified cytoplasmic c-Met protein in wild-type $\left(\mathrm{Met}^{+/+}\right)$pancreatic tissue (Fig. 2C). However, cytoplasmic c-Met was not detected in the $c$-MET knockout MA strain (Fig. 2C).

c-MET expression does not influence the development of pancreatic neoplasia. To examine the development of pancreatic neoplasia, pancreatic tissues were harvested from $\mathrm{CTL}, \mathrm{Km}$ and $\mathrm{KmM} \Delta$ mice at 6 months of age and evaluated by H\&E staining (Fig. 3). This revealed that no pancreatic neoplasia was observed in the pancreatic tissue of CTL mice (Fig. 3A), whereas the pancreatic tissues of $\mathrm{Km}$ (Fig. 3B) and $\mathrm{KmM} \Delta$ mice (Fig. $3 \mathrm{C}$ ) had numerous regions of pancreatic 
A
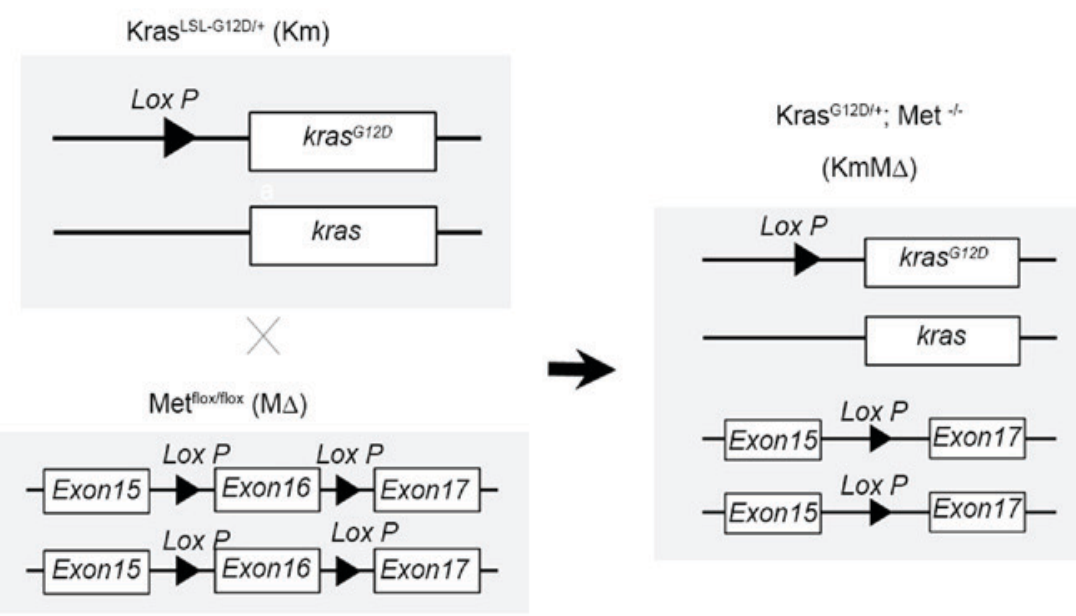

B

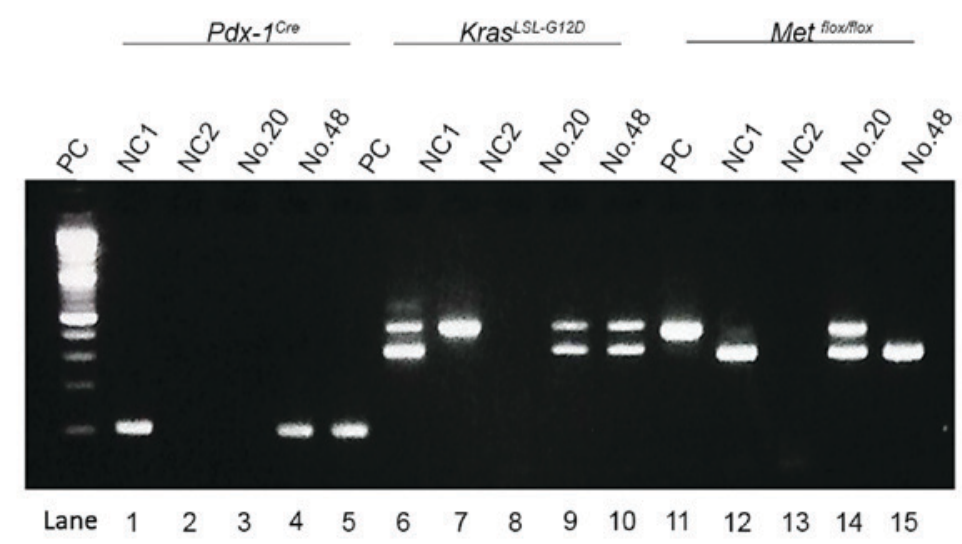

C

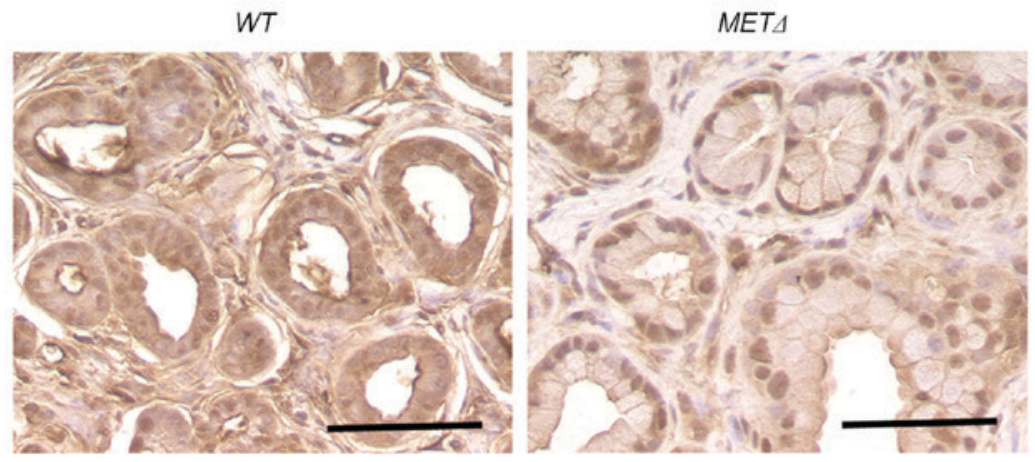

Figure 2. Conditional deletion of the $c-M E T$ allele in the pancreas of $K r a s^{L S L-G I 2 D /+}$ mice. (A) Genetic schema of Km, M $\Delta$ and $\mathrm{KmM} \Delta$ mice. (B) Agarose gel electrophoresis analysis of polymerase chain reaction amplification products of tail DNA from the transgenic mice. In lanes $1-5, P d x-1^{\text {Cre }}$ alleles were detected; in lanes 6-10, low- and high-mobility bands corresponding to wild-type $K R A S$ and $K R A S^{L S L-G I 2 D /+}$ alleles were detected; in lanes 11-15, low- and high-mobility bands indicating wild-type $c-M E T$ and $M E T^{f o x}$ /fox alleles were detected. (C) Representative images of immunohistochemical staining of c-Met in wild-type and conditional c-MET knock-out mice. Scale bar, $100 \mu \mathrm{m}$. PC, positive control; NC1, wild-type; NC2, negative control.

neoplasia. The regions of pancreatic neoplasia observed were positive for Ki-67 (Fig. 3D-F). These results suggest that the cells in regions of neoplasia were proliferating markedly. In $\mathrm{Km}$ and $\mathrm{KmM} \Delta$ mice, ducts and stromal regions were significantly increased and acinar regions were significantly decreased compared with CTL mice (Fig. 3G). Comparison of the tissue sample surface areas indicated that the areas of ducts, acini and stroma were not significantly different between $\mathrm{Km}$ and $\mathrm{KmM} \Delta$ mice (Fig. 3G), suggesting that the absence of endogenous $c$-MET alleles does not affect pancreatic carcinogenesis in pancreas-specific transcription factor Pdx-1-conditional mice ( $P d x-1^{C r e /+}, \mathrm{Kras}^{\mathrm{LSL}-\mathrm{G} 12 \mathrm{D} /+}$ or $\left.\mathrm{Met}^{f l o x / f l o x}\right)$. Survival rates were significantly decreased in $\mathrm{Km}$ and $\mathrm{KmM} \Delta$ mice compared with the CTL mice (Fig. 3H). These results suggest that $c$-MET has little or no impact on the development of pancreatic neoplasia.

c-MET deletion in pancreatic neoplasia enhances chemosensitivity to gemcitabine. Chemoresistance is an important contributory factor to the high mortality rates of the majority of cancer types, including pancreatic cancer. A previous report demonstrated that a high expression of $c-M E T$ in pancreatic cancer is correlated with chemoresistance (10). To examine the role of c-Met in the chemoresistance of pancreatic neoplasia, $125 \mathrm{mg} / \mathrm{kg}$ GEM was administered to CTL, $\mathrm{Km}$ and $\mathrm{KmM} \Delta$ mice. PBS was used as the control treatment. 

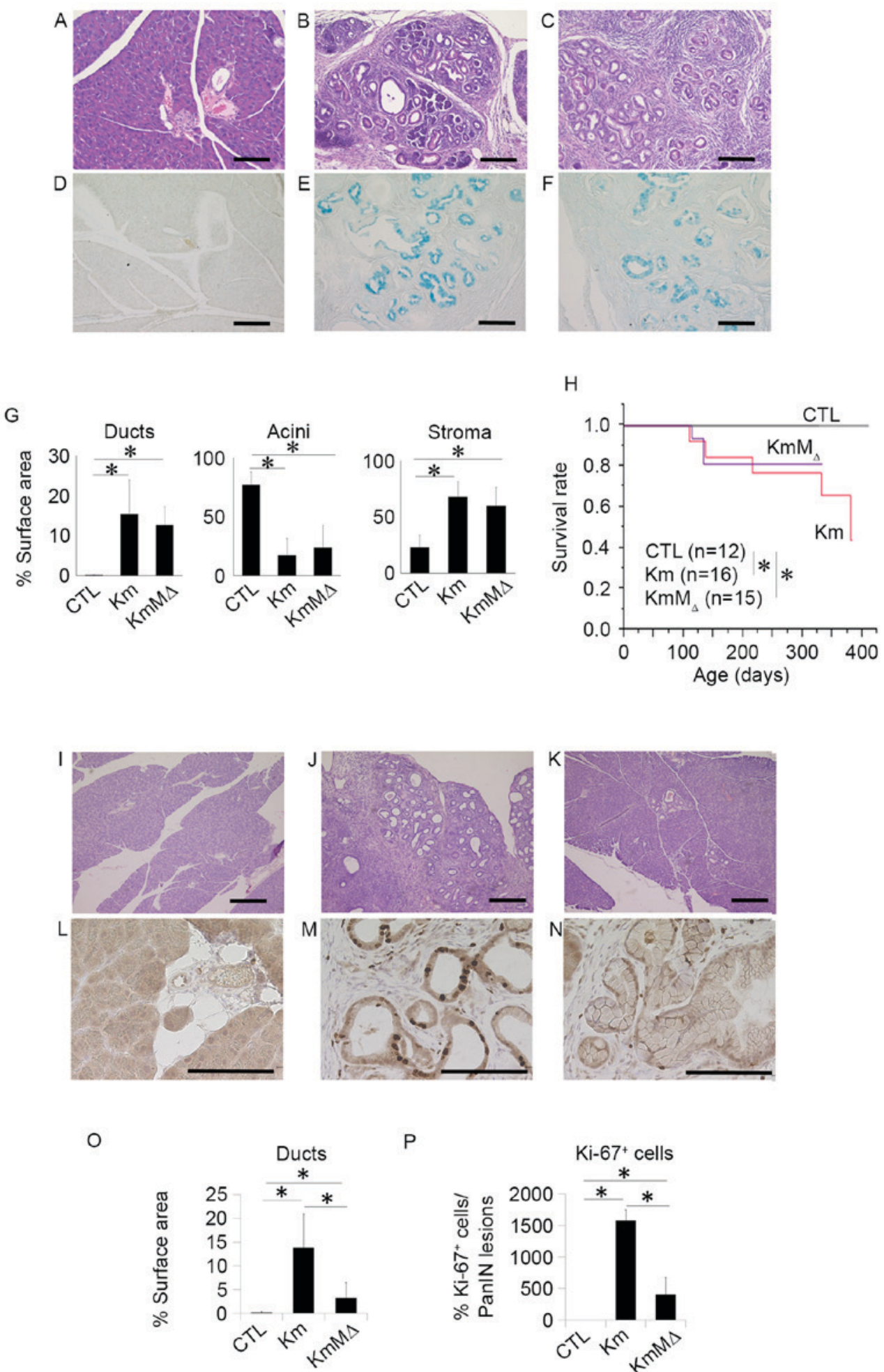

$P$

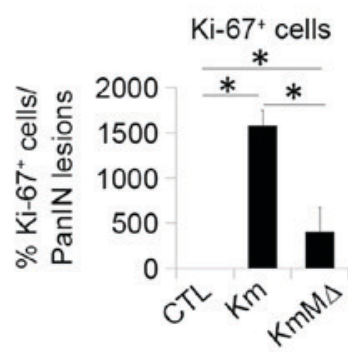

Figure 3. $c-M E T$ expression does not influence the development of pancreatic neoplasia, and $c-M E T$ deletion in pancreatic neoplasia enhances chemosensitivity to GEM. Representative hematoxylin and eosin staining of pancreatic tissue sections from 9-month-old (A) wild-type, (B) $\mathrm{Km}$ and $(\mathrm{C}) \mathrm{KmM} \Delta \mathrm{mice}$. Representative images of alcian blue staining in (D) wild-type, (E) Km and (F) KmM $\Delta$ mice. (G) Quantification of fractional cross sections occupied by ductal lesions, acinar lesions or stroma in wild-type, $\mathrm{Km}$ and $\mathrm{KmM} \Delta$ mice. (H) Kaplan-Meier survival rate of wild-type ( $\mathrm{n}=12), \mathrm{Km}(\mathrm{n}=15)$, and $\mathrm{KmM} \Delta$ mice $(\mathrm{n}=16)$. Histological analysis of the pancreas of (I) wild-type, (J) Km and (K) KmM $\Delta$ mice following $125 \mathrm{mg} / \mathrm{kg}$ GEM administration. Representative immunohistochemistry images of Ki-67 stained (L) wild-type, (M) Km and (N) KmM $\Delta$ mice. (O) Quantification of fractional cross sections occupied by ductal lesions, in wild-type, $\mathrm{Km}$ and $\mathrm{KmM} \Delta$ mice. (P) Quantification of fractional cross sections occupied by Ki-67 positive lesions in wild-type, Km and KmM $\Delta$ mice. Scale bar, $100 \mu \mathrm{m}$. Results are presented as the mean \pm standard deviation $(\mathrm{n}=5)$. ${ }^{*}<0.05$. GEM, gemcitabine; CTL, control wild-type mice.

Histological studies (Fig. 3I-K) revealed that although the relative occupancy of viable PanIN lesions in $\mathrm{Km}$ mice remained at $15 \%$, the amount of PanIN lesions in $\mathrm{KmM} \Delta$ mice was reduced to $<5 \%$ following GEM treatment (data not shown). It has previously been reported that $\mathrm{Ki}-67$ is a useful predictive marker for chemotherapeutic responses and clinical 
prognosis (11). To investigate the cellular proliferation level in the PanIN lesion, Ki-67 staining was performed (Fig. 3L-N). Quantification demonstrated an increase in ductal lesions in $\mathrm{KmM} \Delta$ mice, which was more apparent in $\mathrm{Km}$ mice (Fig. 30). These results demonstrated that $>15 \%$ of $\mathrm{Ki}-67$ positive cells were located in PanIN lesions in Km mice (Fig. 3P).

\section{Discussion}

CSCs typically exhibit three key characteristics, which are not mutually exclusive. Firstly, CSCs are highly tumorigenic and can form tumors in immunodeficient mice through xenotransplantation, which is not possible for non-CSCs (6). Secondly, CSCs that survive chemotherapy and radiotherapy generate resistance to such therapies through regulating intracellular stress; for example, regulating reactive oxygen species, which non-CSCs cannot (12). Thirdly, CSCs possess metastatic potential, illustrated by a report that CSCs have the ability to metastasize through EMT (13).

Previous studies have demonstrated that the expression of c-Met on the cell surface correlates with the characteristics of CSCs. Li et al (14) reported that CSCs with high $c$-MET expression (c-Met ${ }^{\text {hi }}$ ) and cluster of differentiation 44 expression had tumorigenic potential in a NOD/SCID mouse xenograft model. Furthermore, a report has demonstrated that $\mathrm{c}-\mathrm{Met}^{\mathrm{hi}}$ CSCs exhibit resistance to chemotherapy and radiotherapy, and that c-Met inhibitors are effective in the killing of pancreatic cancer cells (15). The signaling pathway downstream of $\mathrm{HGF} / \mathrm{c}-$ Met serves an essential role in the maintenance of pancreatic progenitor cells and stem cells (16). Furthermore, the c-Met/HGF signaling pathway is associated with cancer cell-stroma interactions and the metastasis of therapy-resistant cancer cells (17). Previous studies are in agreement that c-Met serves a role in augmenting the pathological functions associated with the advanced stages of cancer and therapeutic resistance of pancreatic cancer $(4,5,14)$. However, these studies lack in vivo evidence demonstrating the role of c-Met in chemotherapeutic resistance in a pancreatic cancer model. In the present study, c-Met was demonstrated to induce GEM resistance in a mouse model of pancreatic cancer through comparing the surface area of cancerous regions and number Ki-67 positive cells, markers of proliferating malignant cancer cells (11), in $\mathrm{Km}$ and $\mathrm{KmM} \Delta$ mice. Considering that CSCs can survive in a unique hypoxic niche, the present in vivo study of therapeutic resistance in a mouse model has an advantage over previously studied xenograft models, in terms of the microenvironment being more similar to that in human cancer.

Our group previously demonstrated (18) that c-Met ${ }^{\mathrm{hi}}$ pancreatic cancer cells, which have a high capacity for sphere formation (a marker of stemness) and exhibit resistance to GEM, are prone to reprogramming by four transcription factors, proto-oncogene c-Myc, octamer-binding protein 3/4, leucine-rich repeat protein soc-2 and Krueppel-like factor 4. This suggests that CSCs are susceptible to epigenetic reprogramming and that growth factor-dependent intracellular mechanisms are essential for the determination of malignant cancer cell behavior. Although a previous study has demonstrated that the c-Met/HGF signaling pathway induces therapy resistance in CSCs (19), the mechanistic roles that c-Met ${ }^{\text {hi }}$ pancreatic cancer cells serve in regulating cancer stemness during carcinogenesis remain to be elucidated.

The present study demonstrated that pancreatic tumors in $\mathrm{Km}$ and $\mathrm{KmM} \Delta$ mice were formed at a similar frequency, in regards to the formation of ducts, acini and stroma, and that survival rates were not significantly different between $\mathrm{Km}$ and $\mathrm{KmM} \Delta$ mice. Notably, the data also suggested that the absence of c-Met made no significant difference to pancreatic tumor formation. This observation was unexpected, in view of the results of a previous study on therapy-resistant c-Met ${ }^{\text {hi }}$ pancreatic CSCs (20). There are several potential explanations for this observation. Firstly, it is possible that selective activation of the c-Met signaling pathway may be important for the exhibition of characteristic tumor behaviors, including therapy resistance, because $c$-MET amplification and overexpression have been reported to be correlated with worse prognostic significance in gastric cancer (21). $c$-MET expression in transgenic mice may cause carcinogenesis, although the present study used conditional knockout model. Secondly, as chronic inflammatory responses coexist with pancreatic cancer formation (22), the present study was designed to examine the essential role of c-Met. The use of transgenic mice that had this inflammatory environment present, including the relevant cytokines and chemokines, may therefore have influenced carcinogenesis in the pancreas. Thirdly, the present study used a pancreatic and duodenal homeobox (Pdx)-1 promoter-driven conditional knockout for KRAS mutant activation in addition to $\mathrm{c}$-Met knockout. Although Pdx-1 is expressed in stem and progenitor cells in the pancreas, the function of Pdx-1 appears to be context-dependent in cancer development, in which an interplay of multiple transcription factor networks is involved (23). These results suggest that endogenous c-Met serves an essential role in therapy resistance, which may be enhanced by the increased expression of endogenous c-Met, potentially as a result of gene amplification. This appears to be in contrast to the initiation of pancreatic carcinogenesis, where multiple factors serve a role. This notion is analogous with clinical observations in humans, demonstrating a role of c-met in the early stage of pancreatic carcinogenesis (24). Thus, inhibitors of c-Met may be beneficial for the control of therapy-resistant CSCs (15).

In conclusion, the present study used conditional knockout of the $c$-Met gene in mice carrying a KRAS mutation to investigate the role of $\mathrm{c}-\mathrm{Met}$ in pancreatic cancer development and therapy resistance. c-Met was identified to serve a role in GEM resistance in vivo. As amplification and altered expression of the $c-M E T$ gene is apparent in gastrointestinal cancer, the results of the present study suggest that targeting the c-Met signaling pathway is a potential option for the treatment of pancreatic cancer and warrants further study.

\section{Acknowledgements}

The authors thank all members of our laboratories for helpful discussion and technical assistance.

\section{Funding}

The present study was supported in by the Ministry of Education, Culture, Sports, Science and Technology of Japan (http://www.mext.go.jp/english; grant nos. 23390199, 
25112708, 25134711, 30253420 and 26670604); P-DIRECT (Hideshi Ishii); the Ministry of Health, Labor and Welfare of Japan (http://www.mhlw.go.jp/english; grant no. H23-003); the National Institute of Biomedical Innovation (http://www. nibio.go.jp/english/index.html; grant no. 12-4); and the Osaka University Drug Discovery Fund (http://www.osaka-u. ac.jp/en/index.html) (Masaki Mori and Hideshi Ishii). Partial support was received from the Takeda Science and Medical Research Foundation (http://www.takeda-sci.or.jp/index.html) (Hideshi Ishii), the Princess Takamatsu Cancer Research Fund (http://www.ptcrf.or.jp/english) (Masaki Mori, Hideshi Ishii), the Suzuken Memorial Foundation (http://www.suzukenzaidan. or.jp) (Masamitsu Konno), the Yasuda Medical Foundation (http://www.yasuda-mf.or.jp) (Naohiro Nishida), the Pancreas Research Foundation (http://www.jprf.or.jp/shoreisho.html) (Koichi Kawamoto), the Nakatani Foundation (http://www. nakatani-foundation.jp), and the Nakatomi Foundation, Japan (https://www.nakatomi.or.jp/en/index.html) (Masamitsu Konno). Institutional endowments (grants) were received from TaihoPharmaceuticalCo.,Ltd.(http://www.taiho.co.jp/english), Evidence Based Medical Research Center (http://ebmrce. co.jp/index.html), Chugai Co., Ltd. (http://www.chugai-pharm. co.jp/english/index.html), Yakult Honsha Co., Ltd. (http:// www.yakult.co.jp/english/index.html), and Merck Co., Ltd. (http://www.merck.co.jp/en/index.html).

\section{Author's contributions}

The experiments were performed by KN, MK, KK, NN, JK, $\mathrm{HW}$ and HA. The analysis of data was performed by KN, MK, HE, KK, RM and TS. The manuscript was written by KN, MK, MM and HI. The study was designed by TS, SM, HN, YD, MM and HI.

\section{Ethics approval and consent to participate}

All animal studies were approved by the Animal Experiments Committee of Osaka University (Osaka, Japan; approval no. 24-122-022).

\section{Consent for publication}

Not applicable.

\section{Competing interests}

The authors declare that they have no competing interests.

\section{References}

1. Howe HL, Wu X, Ries LA, Cokkinides V, Ahmed F, Jemal A, Miller B, Williams M, Ward E, Wingo PA, et al: Annual report to the nation on the status of cancer, 1975-2003, featuring cancer among U.S. Hispanic/Latino populations. Cancer 107: 1711-1742, 2006.

2. Majumder K, Gupta A, Arora N, Singh PP and Singh S: Premorbid obesity and mortality in patients with pancreatic cancer: A systematic review and meta-analysis. Clin Gastroenterol Hepatol 14: 355-368.e, 2016.

3. Pandol S, Gukovskaya A, Edderkaoui M, Dawson D, Eibl G and Lugea A: Epidemiology, risk factors, and the promotion of pancreatic cancer: Role of the stellate cell. J Gastroenterol Hepatol 27 (Suppl 2): S127-S134, 2012.
4. Rizwani W, Allen AE and Trevino JG: Hepatocyte growth factor from a clinical perspective: A pancreatic cancer challenge. Cancers (Basel) 7: 1785-1805, 2015.

5. Ide T, Kitajima Y, Miyoshi A, Ohtsuka T, Mitsuno M, Ohtaka K and Miyazaki K: The hypoxic environment in tumor-stromal cells accelerates pancreatic cancer progression via the activation of paracrine hepatocyte growth factor/c-Met signaling. Ann Surg Oncol 14: 2600-2607, 2007.

6. Reya T, Morrison SJ, Clarke MF and Weissman IL: Stem cells, cancer, and cancer stem cells. Nature 414: 105-111, 2001.

7. Lonardo E, Hermann PC, Mueller MT, Huber S, Balic A, Miranda-Lorenzo I, Zagorac S, Alcala S, Rodriguez-Arabaolaza I, Ramirez JC, et al: Nodal/Activin signaling drives self-renewal and tumorigenicity of pancreatic cancer stem cells and provides a target for combined drug therapy. Cell Stem Cell 9: 433-446, 2011.

8. Asukai K, Kawamoto K, Eguchi H, Konno M, Nishida N, Koseki J, Noguchi K, Hasegawa S, Ogawa H, Yamada D, et al: Prognostic impact of peritumoral IL-17-positive cells and IL-17 axis in patients with intrahepatic cholangiocarcinoma. Ann Surg Oncol 22 (Suppl 3): S1524-S1531, 2015.

9. Bai H, Li H, Zhang W, Matkowskyj KA, Liao J, Srivastava SK and Yang GY: Inhibition of chronic pancreatitis and pancreatic intraepithelial neoplasia (PanIN) by capsaicin in LSL-KrasG12D/Pdx1-Cre mice. Carcinogenesis 32: 1689-1696, 2011.

10. Shah AN, Zhang JM, Park SI, Parikh NU and Gallick GE: Development and characterization of gemcitabine-resistant pancreatic tumor cells. Ann Surg Oncol 14: 3629-3637, 2007.

11. Koh YX, Chok AY,Zheng HL, Tan CS and Goh BK: A systematic review and meta-analysis of the clinicopathologic characteristics of cystic versus solid pancreatic neuroendocrine neoplasms. Surgery 156: 83-96.e2, 2014.

12. Wu WS: The signaling mechanism of ROS in tumor progression. Cancer Metastasis Rev 25: 695-705, 2006.

13. Mani SA, Guo W, Liao MJ, Eaton EN, Ayyanan A, Zhou AY, Brooks M, Reinhard F, Zhang CC, Shipitsin M, et al: The epithelial-mesenchymal transition generates cells with properties of stem cells. Cell 133: 704-715, 2008.

14. Li C, Wu JJ, Hynes M, Dosch J, Sarkar B, Welling TH, Pasca di Magliano M and Simeone DM: c-Met is a marker of pancreatic cancer stem cells and therapeutic target. Gastroenterology 141: 2218-2227.e5, 2011.

15. Christensen JG, Schreck R, Burrows J, Kuruganti P, Chan E, Le P, Chen J, Wang X, Ruslim L, Blake R, et al: A selective small molecule inhibitor of c-Met kinase inhibits c-Met-dependent phenotypes in vitro and exhibits cytoreductive antitumor activity in vivo. Cancer Res 63: 7345-7355, 2003.

16. Oshima Y, Suzuki A, Kawashimo K, Ishikawa M, Ohkohchi N and Taniguchi H: Isolation of mouse pancreatic ductal progenitor cells expressing CD133 and c-Met by flow cytometric cell sorting. Gastroenterology 132: 720-732, 2007.

17. Ohuchida K, Mizumoto K, Murakami M, Qian LW, Sato N, Nagai E, Matsumoto K, Nakamura T and Tanaka M: Radiation to stromal fibroblasts increases invasiveness of pancreatic cancer cells through tumor-stromal interactions. Cancer Res 64: 3215-3222, 2004.

18. Noguchi K, Eguchi H, Konno M, Kawamoto K, Nishida N, Koseki J, Wada H, Marubashi S, Nagano H, Doki Y, et al: Susceptibility of pancreatic cancer stem cells to reprogramming. Cancer Sci 106: 1182-1187, 2015.

19. Awad AJ, Burns TC, Zhang Y and Abounader R: Targeting MET for glioma therapy. Neurosurg Focus 37: E10, 2014.

20. Herreros-Villanueva M, Zubia-Olascoaga A and Bujanda L: c-Met in pancreatic cancer stem cells: Therapeutic implications. World J Gastroenterol 18: 5321-5323, 2012.

21. Peng Z, Zhu Y, Wang Q, Gao J, Li Y, Li Y, Ge S and Shen L: Prognostic significance of MET amplification and expression in gastric cancer: A systematic review with meta-analysis. PLoS One 9: e84502, 2014.

22. Inman KS, Francis AA and Murray NR: Complex role for the immune system in initiation and progression of pancreatic cancer. World J Gastroenterol 20: 11160-11181, 2014

23. Pedica F, Beccari S, Pedron S, Montagna L, Piccoli P, Doglioni C and Chilosi M: PDX-1 (pancreatic/duodenal homeobox-1 protein 1). Pathologica 106: 315-321, 2014.

24. Yu J, Ohuchida K, Mizumoto K, Ishikawa N, Ogura Y, Yamada D, Egami T, Fujita H, Ohashi S, Nagai E and Tanaka M: Overexpression of c-met in the early stage of pancreatic carcinogenesis; altered expression is not sufficient for progression from chronic pancreatitis to pancreatic cancer. World J Gastroenterol 12: 3878-3882, 2006. 